\title{
The Future of the City after COVID-19: Digitionalization, Preventism and Environmentalism
}

\author{
Julia M. Puaschunder ${ }^{1,2}$ \\ ${ }^{1}$ The New School, Department of Economics, 6 East $16^{\text {th }}$ Street, $9^{\text {rd }}$ floor 89, New York, NY 10003, USA, \\ Julia.Puaschunder@newschool.edu,T001212229 5700,F 001212229 5724,www.juliampuaschunder.com \\ ${ }^{2}$ Columbia University, Graduate School of Arts and Sciences, Julia.Puaschunder@columbia.edu, \\ http://blogs.cuit.columbia.edu/jmp2265
}

\begin{abstract}
Ever since, metropolitan areas have seen a resurgence of the city as a hub for exchange of ideas, social transformation and innovation. Since the ages of industrialization and globalization, cities flourished in terms of economic growth and societal advancement. The 2020 COVID-19 crisis may set an end to this. Some of the major cities and foremost Western world metropolis began to empty out with the rapid rise of an infected city population due to social transfer of the pandemic and worsened diseases outcomes in a constraint medical system in high density areas. Even if the COVID-19 will be defeated with a vaccine or overcome with herd immunity during the coming years, the economy of large cities may be permanently changed given an ongoing digitalization trends, preventive medical care attention and environmental concerns in the wake of climate change. This paper envisions these three new trends of globalization shifting cityscaping to digitalization, focus on preventive medical care and environmental conscientiousness in future cities.
\end{abstract}

KEYWORDS: cities, Coronavirus, COVID-19, digitalization, economic growth theory, healthcare, human capital, inequality, innovation, international development, lockdowns, pandemics, preventive healthcare, urban economics, urbanism, workforce

\section{Cities}

Adam Smith's Wealth of Nations described the miracle of cities already in 1776. Metropolitan areas were envisioned as social transformation hubs that allowed country populations coming from the country side to ward off the shackles of their birth status and feudal dependency. In the countryside well-being was also directly related to weather and the overall environmental conditions.

Thanks to exchange in cities and the luxury of trade via the means of exchange of money given as remuneration, the city population could engage in common production endeavors. For their productive labor power individuals were remunerated based on productivity, effort and motivation in cities. Funds as a means of exchange enabled trade in cities and the specialization on one particular task, which the city worker could focus on. Cities have therefore ever since Adam Smith become known as ultimate social transformation hubs, in which people can aspire, thrive and succeed in economic prosperity and social uprise.

Ever since, cities enabled true miracles of specialization, where one could enjoy the best outcomes of everyone else's specialized peak performance. Anonymity of the city could push people's imagination of who they wanted to be. Performance thereby lifted to selfaspired higher levels than the urban socially constraint population, who was assured of their social class stickiness by feudal lords. Metropolitan entrepreneurs could align productive workforce, while workers could specialize on one piece of production and become the experts in it. The mere nature of cities allowing for exchange of goods and services on a fast pace and with easy access of a rising and diverse population thus leveraged specialization to excellence. 
Since the age of enlightenment, cities offered the luxury of anonymity, where those who wanted to work gathered to be judged on their actual today's performance. Being remunerated by societal contribution rather than where one came from and what social class one was born into, but also being free to choose a profession based on skills and passion as well as being remunerated by the supply-demand echo of markets allowed anyone who dared to come to the metropolitan world to cast off the shackles of classes, natal status and prosperity dependent on the whims of nature. Cities thus served as birthplace of concentrated political transformation and lasting social change.

So not only account cities as social transformation hubs ever since, urban areas have also become the epicenters of trend breakers thanks to high levels of density, first-mover advantage due to favorable trade locations as well as anonymity benefits. The city population can celebrate exchange of the most refined goods and services thanks to density of ideas that are exchangeable on a fast pace in the constraint space. Highly specialized urban hubs that portray excellence attract a sophisticated, educated and wealthy populace. From all over the world, ambitious human capital amassed in large metropolis, where innovation naturally happens. The elite gathered together in cities aspires to consume highly-specialized goods and services. Together cadres of specialized workers could then focus on reaping network effects benefiting uniquely from exponentially-rising marginal utility in exchange of ideas, transfer of knowledge and inspiration of bundled arts, sciences and industry hubs.

Often historically located in transit points and gateways to multiple other worlds, cities have become harbors of goods, services and ideas. Metropolitan areas grant first-hand access to refined goods of entry ports. In addition, a lavish repertoire of entertainment is enjoyed together with gifted others around allows for cross-pollination in arts, communication, sciences, fashion, food and luxury flourishing. International influences closely-together in the metropolis and encouraged to exchange on a constant basis in dense areas, leveraged cities as epicenters to break trends. Trends grew out of these metropolitan areas around the world and ignited social change thereafter around the globe. No matter where exactly in the world, cities advanced cultural and intellectual development of populations around the globe despite the vast differences in historical times, traditions, religions and regimes.

Because of the network effect of large numbers of innovators coming together, exchanging ideas on a fast pace and being forced to push for one's own agenda under time constraints of temporary work placements and high expenses for comparatively high city rents, urban areas have contributed uniquely to economic growth. Especially during the past centuries, cities have been hubs of innovation, where individuals seeking to succeed in business, technology, culture, and academia have come together, as well as to cast off the strictures of rural and suburban life. In recent decades, the United States and other wealthy countries have seen a resurgence of the city in terms of population and as a hub for economic growth and transformational innovation.

\section{COVID-19}

The currently ongoing 2020 COVID-19 crisis seems to have set an end to these metropolitan trends. Some of the major cities began to empty out in March 2020, when the workforced changed to online and remote workspaces. Most of the productive parts of cities left temporarily to avoid contagion, and many made their departure permanent during the summer of the same year. COVID-19 may have permanently altered access to metropolitan benefits because it came at a time when the world was ripe for digital disruption offering novel luxuries of truly international exchange of ideas in a newly emerging digital world. In deciding whether to live in a city or remain in a rural area, individuals with a high earnings potential today faced a trade-off between better opportunities to benefit from unique network effects, but higher costs of city life 
for housing, schooling, property taxes and risks to health and safety due to the pandemic and lockdown-related crime. We now may have reached an irreversible tipping point in comparison to previous pandemics, tragedies and terrorist threats to metropolitan bundles of human concentration. Especially those fields that traditionally benefited most from the city network effect have proven to be able to shift much of their activity into cyberspace by allowing remote work - for instance some of the large technology companies completely transitioning to a remotely working taskforce. The city premium has thus shrunk, while the cost of city life has not yet adjusted downwards. But how will the post-COVID-19 digital globe now e-urbanize?

In the course of the inevitable adjustment during the coming years, we are likely to see an increasing trend toward a world that is truly flat, with network benefits being reaped virtually. The highly educated and technology versed workforce of tomorrow will likely enjoy all the benefits a rural life physically but work in a truly global life virtually.

COVID-19 having exacerbated healthcare and hygiene needs will likely change individuals' preference for healthy breeding grounds in health-conscientious environments. Future city management will address these trends with shifts into healthy lifestyle promoting and hygiene enabling city features. Open space and social distancing but also easily accessible cleaning possibilities are perks of future cities.

Environmental conscientiousness will likely gain higher attention with individuals moving back into the countryside for social distancing purposes. With city populations moving to rural areas and travels to outskirts ruling over airborne travels, individuals will reconnect with nature and environmental attention will become accentuated. Already now we see attention to local communities rising. With the age of globalization having halted, we will likely return to a more environmentally sound living that pays attention to the larger environmental impact of individuals' footprint for this generation and the following.

\section{Future cities of tomorrow}

Digitionalization:

Specialization, which was perfected in cities, may become more global and international in a digitalized world, a trend which I may call digitionalization representing the ongoing globalization in digital spaces. With the internet as a window to the world, trends online have become truly global. May it be fundraising, communication, social mingling, shopping or education. The world has become flat online in breaking trends in an unprecedentedly fast changing range and mix of social media tools and features. Trends can emerge from all parts of the world now and compete for the idea rather than a brand-name of a city that signals money spent on housing, schooling, property taxes and social skills of its inhabitants or huge budgets for travel expenses of those trying to participate.

Especially those fields that traditionally benefited most from the city network effect have proven to be able to shift much of their activity into cyberspace by allowing remote work instantaneously. The city premium has thus shrunk, while the cost of city life has not yet adjusted downwards. In the course of the inevitable adjustment during the coming years, we are therefore likely to see an increasing drive toward a world that is truly flat, with network benefits being reaped virtually with the highly educated workforce decamping to rural and suburban areas.

Historically, cities were social transformation hubs but with COVID-19 cities are empty as the population is in strict lockdown mode. Nowadays, social online media have taken over the role as social accelerators of trends. Social online crowds are also putting enormous pressure on companies, public institutions, but also individuals and politicians. Social media and online forums encourage transparency and online group dynamics, which can quickly break trends. Today's social online media landscape now also leads a trend towards social censorship online. The historical governmental privilege to censor has shifted nowadays to an online mob that practices social censorship online in the digital age. This 
requires an enlightened culture of freedom of expression, as advocated by Voltaire and Rousseau in the 18th century.

The cloak of anonymity is perpetuated online, where one can truly be what one wants to portray. Family ties or heritage become even less transparent in a virtual illusion that can emerge from anywhere around the world. More than ever before in the long history of city gatherings, does online anonymity free from shackles of social class and nepotism. But in the digital age, anonymity has also brought along problems of cyber-crime, hate postings and social censorship. When online platform providers are boycotted by companies, in the event that they do not censor non-mainstream opinions, one might even think that this represents an end to liberalism. Nowadays, publicly expressed opinions have to be adapted to a social, media-compliant opinion and sometimes may not reflect the attitude shaped by one's own experience. Freedom of expression should therefore be protected. Harper's Magazine has therefore called for a Letter on Justice and Open Debate that is currently being signed by influential opinion leaders around the world. Attention should be paid to discrimination against excellence, namely that no room is given to the loudest and most aggressive group censoring the internet, but excellent individual points of view are also been tolerated (Puaschunder 2020).

So when closing to comment on the digital urbanism happening as of now, we may urge to uphold e-ethics and digital codes of conduct. Future living will entail people being in less densely populated areas at favorable prices in higher-quality-of-living natural resorts. For exchange of ideas and goods, they will likely delve into world-wide collective virtual city experiences that are most internationally-specialized and virtually-anonymous where they can enjoying lavish network effects. In virtual spaces everyone can truly be whoever they want to be and spend their time on whatever they want. But these priceless online havens also bear a responsibility to worship our common virtual luxury temples together wisely, conscientiously and sustainably (Puaschunder 2018, 2019, 2020a, b, forthcoming a).

\section{Preventism}

With the novel Coronavirus (COVID-19) spreading around the world from the beginning of 2020 on, calls are made that the medicine of the future should prevent diseases instead of just treating their consequences. In the novel Coronavirus crisis, prevention and general, holistic medicine determine whether COVID-19 puts patients on a severe or just mild symptom trajectory. Obesity, but also the general status of the immune system are decisive in whether the Coronavirus becomes a danger for the individual. The COVID-19 crisis is therefore an important accelerator for necessary, fundamental changes in the health system, which also results in ecological impacts as a healthy diet is usually less carbon intensive.

The COVID-19 pandemic featuring different trajectories based on prevalence and the general health status and immune system, has created attention for prevention rather than simply curing consequences of diseases. Because we have to live with viruses and other environmental burdens on our health that are increasing due to rapid climate change, a change of direction towards prevention is expected to take place. Chronic diseases and their therapy are treated most successfully if the context of health and disease is considered from a systems biology perspective.

Individuals, families, workteams, corporate managers and governance officials will start to realize that promoting a healthy lifestyle in a favorable environment will help implementing prevention. Besides focusing on a healthy, ecological diet, also taking into account the health of our planet and climate attention, practicing epidemic hygiene will play a major role in the cities of tomorrow. Cities will focus on general hygiene and health and safe environmental conditions. Health will become a general theme of business, ecology and politics of city planning. Insurances will become a major part of preventive risk 
minimization. Return-on-investment and sales for GDP as a rating of success should also integrate the long-term state of the overall health of the workforce and environmental conditions of the nation. In this light, the "homo oeconomicus" is outdated by the "homo praeventicus" stressing the need for shifting a purely economic outlook to at least integrating disease prevention and fostering an overall healthy lifestyle (Puaschunder forthcoming b).

\section{Ecowellness trends}

Moving from large cities to more rural areas will reconnect individuals with environmental conditions during a crucial time in light of climate change. Today, there is a heightened demand for climate stabilization featuring concerted mitigation and adaptation efforts. Different environmental efforts could shape the global environmental governance required in the $21^{\text {st }}$ century, ranging from formal institutions (major global conferences and treaties), legal regimes, informal arrangements, intergovernmental relationships, nongovernmental organizations, global capital markets and multinational corporations (Puaschunder forthcoming c). Attempts to curb human-made carbon emissions that are offsetting the climate change dilemma may be in contrast to economic growth. For instance, fiscal policies and carbon tax but also monetary and credit policies attentive to environmental degradation may curb productivity. Creative ecowellness options and sustainable lifestyle innovations may emerge that pay tribute to health and well-being within the given natural constraints of ecological limits. Future cities may also see ecologic pricing reforms that pay tribute to the trend into environmentalism. Active cityscape projects may feature forestation to absorb $\mathrm{CO}_{2}$ from the atmosphere but also behavioral changes. Already now we find a trend towards individualized cars and further behavioral changes will likely force transportation to become more hygienic and individualized. Lastly, the cities of tomorrow will likely feature intergenerational conscientiousness in protecting elder and low immune system risk groups from contagious diseases.

\section{References}

Puaschunder, Julia Margarete. 2018. "Dignity and utility of privacy and information sharing in the digital big data age." International Journal of Commerce and Management Research 5(4):6270 .

Puaschunder, Julia Margarete. 2019. "Artificial diplomacy: A guide for public officials to conduct Artificial Intelligence." Journal of Applied Research in the Digital Economy 1: 39-45.

Puaschunder, Julia Margarete. 2020a. Data fiduciary in order to alleviate principal-agent problems in the artificial big data age. 46th Eastern Economic Association Conference, Boston Sheraton, Boston, Massachusetts, United States, February 29, 2020.

Puaschunder, Julia Margarete. 2020b. On freedom in the artificial age. Retrieved at https://papers.ssrn.com/sol3/papers.cfm?abstract_id=3544348.

Puaschunder, Julia Margarete. forthcoming a. "Big data ethics." Journal of Applied Research in the Digital Economy 1: 55-75.

Puaschunder, Julia Margarete. forthcoming b. "From homo oeconomicus to homo praeventicus." 19th Research Association for Interdisciplinary Studies (RAIS) conference at Princeton University, Princeton, New Jersey, United States, October 18-19, [Held online due to COVID-19].

Puaschunder, Julia Margarete. forthcoming c. "Overambition as disability: Discrimination of excellence." 19th Research Association for Interdisciplinary Studies (RAIS) conference at Princeton University, Princeton, New Jersey, United States, October 18-19. [Held online due to COVID-19]

Smith, Adam. 1776. An inquiry into the nature and causes of the wealth of nations. Retrieved online at https://books.google.com/books?id=C5dNAAAAcAAJ\&pg=PP7\#v=onepage\&q\&f=true. 